\title{
Small-sized gold nanoparticles inhibit the proliferation and invasion of SW579 cells
}

\author{
QINGQING ZHANG, YONGMEI MA, SHUFANG YANG, BANGKUI XU and XIAOQIANG FEI \\ Department of Endocrinology, Taizhou People's Hospital, Taizhou, Jiangsu 225300, P.R. China
}

Received December 14, 2014; Accepted September 24, 2015

DOI: $10.3892 / \mathrm{mmr} .2015 .4433$

\begin{abstract}
The present study reported on an intrinsic property of gold nanoparticles (Au-NPs), namely their ability to inhibit the proliferation and invasion of thyroid carcinoma cells. Au-NPs of various sizes (5-60 nm) were synthesized and their uptake into the SW579 human thyroid carcinoma cell line was verified using transmission electron microscopy (TEM). The viability, apoptosis, cell cycle distribution and invasive capacity of SW579 cells were assessed following treatment with Au-NPs using a Cell Counting Kit-8 assay, flow cytometric analysis and a Transwell as well as a fluorometric invasion assay. TEM demonstrated that all sizes of Au-NPs could be taken up by the SW579 cells. The results showed that small-sized Au-NPs (5 and $10 \mathrm{~nm}$ ) significantly suppressed the proliferation and invasion of SW579 cells and induced apoptosis as well as cell cycle arrest in G0/G1 phase, while larger-sized gold nanoparticles $(20-60 \mathrm{~nm}) \mathrm{did}$ not exert these effects, therefore suggesting that the effects of Au-NPs on SW579 cells were highly associated with their particle size. The reduction of the invasive capacity of SW579 cells following treatment with Au-NPs may be attributed to decreases in the expression of matrix metalloproteinase-2 and -9 , which were observed using western blot and reverse-transcription quantitative polymerase chain reaction analyses. The present study was the first to demonstrate that small-sized Au-NPs inhibit the proliferation and invasion of thyroid carcinoma cells, which may contribute to the advancement of biomedical applications of Au-NPs.
\end{abstract}

\section{Introduction}

In spite of extensive research efforts regarding the biomedical applications of functionalized nanoparticles (NPs), the anti-cancer effects of certain unmodified NPs have remained

Correspondence to: Miss. Xiaoqiang Fei, Department of Endocrinology, Taizhou People's Hospital, 210 Yingchun Road, Taizhou, Jiangsu 225300, P.R. China

E-mail: 18061986120@189.cn

Key words: proliferation, invasion, SW579, gold nanoparticles to be studied in detail. At present, Au-NPs are utilized in various biomedical applications, including intracellular gene regulation, chemotherapy and drug delivery, as well as in optical and electronic applications (1-3). Not only can Au-NPs be used as scaffolds for the delivery of anti-cancer drugs to enhance their potency, but they can also serve as intrinsic anti-neoplastic agents (4-6). A previous study demonstrated that unmodified Au-NPs inhibited the proliferation of cancer cells by abrogating mitogen-activated protein kinase signaling (7).

The benefits of nanomaterials in biomedical and industrial applications for human health and the environment have been demonstrated by a large number of studies $(8,9)$. Detailed studies on the broad applications of Au-NPs are available, indicating their size-dependent physicochemical and biological properties. Arvizo and Murphy (10) demonstrated that small Au-NPs (diameter, $<2 \mathrm{~nm}$ ) were able to penetrate the cell nucleus, rendering them highly toxic. However, Connor et al (11) found that Au-NPs with a diameter of 4, 12 and $18 \mathrm{~nm}$ were able to be endocytosed by cells, while not showing any inherent toxicity to leukemia cells. As these previous studies indicated differential effects of Au-NPs depending on their size, further elucidation of their properties and determination of a suitable particle size for cancer therapy are required.

The anti-metastatic properties of Au-NPs are the focus of current research (12). The process of cell invasion and metastasis begins with cell proliferation, followed by dissociation of single cells from the primary lesions and their migration via the blood or lymph system, finally leading to adhesion to a secondary site of the body (13). In spite of marked progress in surgery, chemotherapy and radiotherapy, tumor recurrence is almost inevitable once metastasis is present $(14,15)$. Previous studies have demonstrated that matrix metalloproteinase (MMP)2 and MMP9, used as prognostic biomarkers for thyroid carcinoma progression, have important roles in cancer cell adhesion, invasion and migration (16-18).

Therefore, the present study assessed the effects of $\mathrm{Au}-\mathrm{NPs}$ on the proliferation, invasion and expression of MMPs in human thyroid carcinoma, which is a major malignant tumor type in China with an increasing incidence rate (19). The effects of Au-NPs of various sizes $(5,10,20,40$, 50 and $60 \mathrm{~nm}$ ) on the proliferation and invasion of the SW579 cell line were assessed in order to provide a foundation for the application of Au-NPs in thyroid carcinoma therapy. 


\section{Materials and methods}

Synthesis of Au-NPs. The classic citrate reduction method was used to synthesize Au-NPs (20). For each synthesis, $100 \mathrm{ml}$ $0.01 \% \mathrm{HAuCl}_{4}$ solution (Sinopharm Chemical Reagent Co., Ltd, Beijing, China) was heated to boil. Aliquots of $1 \%$ citrate solution (Shanghai XiBao Biological Technology Co., Ltd., Shanghai, China) were added, followed by heating to boil until the color of the solution turned to red. The solution was allowed to cool to room temperature (RT), and the morphology of the Au-NPs was observed by transmission electron microscopy (TEM; JEM-2100EX, JEOL, Ltd., Tokyo, Japan). The nanoparticles were purchased from Southeast University Biological and Medical Nanotechnology Research Laboratory (Nanjing, China).

Cell culture. The SW579 human thyroid carcinoma cell line (Shanghai Institutes for Biological Sciences, Chinese Academy of Sciences, Shanghai, China), were cultured in RPMI-1640 medium containing 10\% (v/v) fetal bovine serum (FBS), $100 \mathrm{U} / \mathrm{ml}$ penicillin and $100 \mu \mathrm{g} / \mathrm{ml}$ streptomycin (all from Gibco (Thermo Fisher Scientific, Waltham, MA, USA) at $37^{\circ} \mathrm{C}$ in a humidified atmosphere containing $5 \% \mathrm{CO}_{2}$. Cells were harvested using trypsin-EDTA (Gibco) at the logarithmic growth phase, followed by centrifugation at $300 \mathrm{x} g$ for $5 \mathrm{~min}$ and re-suspension in RPMI-1640 containing 10\% FBS. In the experiments, cells were treated either with or without $50 \mu \mathrm{g} / \mathrm{ml}$ Au-NP solution for $24 \mathrm{~h}$ prior to subsequent analyses.

TEM studies. The uptake of Au-NPs by the cells was observed using TEM. Prior to incubation with the Au-NPs, the SW579 cells were seeded into 100-mm dishes (Corning Inc., Corning, NY, USA) at $1 \times 10^{6}$ cells per dish and incubated for $24 \mathrm{~h}$. After subsequent incubation with Au-NPs for $24 \mathrm{~h}$, the cells were fixed in $3.7 \%(\mathrm{v} / \mathrm{v})$ paraformaldehyde (Beijing Dingguochangsheng Biotech Co., Ltd., Beijing, China) for $20 \mathrm{~min}$ at RT. The cells were then prepared for TEM analysis as follows: Cells were fixed in $1 \%(\mathrm{w} / \mathrm{v})$ osmium tetroxide (Shanghai WeiHuan Biotech Co., Ltd., Shanghai, China) for $2 \mathrm{~h}$, dehydrated in a graded series of 30, 50, 70, 80 and 90\% ethanol, and treated three times with $100 \%$ ethanol for 15 min each. The samples were then embedded in a mixture of resin (Shanghai Absin Bioscience Inc., Shanghai, China) in propylene oxide (Shanghai WeiHuan Biotech Co., Ltd.) polymerized at $80^{\circ} \mathrm{C}$. Ultrathin sections $(75 \mathrm{~nm})$ were produced using a diamond knife and the samples were analyzed by TEM (JEM-2100EX; JEOL, Ltd.).

Cell Counting Kit (CCK)-8 assay. SW579 cells, seeded in 96-well plates $(2,000$ cells/well), were allowed to attach overnight and then left untreated or treated with Au-NPs (5, $10,20,40,50$ or $60 \mathrm{~nm}$ ) for $24 \mathrm{~h}$. Subsequently, assay reagent (cat. no. KGA317; Cell Counting Kit-8; Kaiji, Nanjing, China) was added to each well followed by an incubation for 1, 2, 3 and $4 \mathrm{~h}$. Absorbance values at $450 \mathrm{~nm}$ were recorded using a microplate reader (iMark Microplate Absorbance Reader; Bio-Rad Laboratories, Inc., Hercules, CA, USA), the results from each of the four time points were averaged, and the cell viability was calculated as a percentage of the untreated control. Each experiment was performed in triplicate wells and the experiment was repeated three times.
Apoptosis detection by Annexin V-propidium iodide (PI) staining. SW579 cells, seeded onto a six-well culture plate at a density of $1 \times 10^{5}$ cells per well, were and allowed to attach overnight in a $37^{\circ} \mathrm{C}$ incubator. After treatment with or without Au-NPs $(5,10,20,40,50$ or $60 \mathrm{~nm})$ for $24 \mathrm{~h}$, apoptosis and necrosis were analyzed using the Annexin V-PI apoptosis detection kit (cat. no. 556547; BD Biosciences, Franklin Lakes, NJ, USA) following the manufacturer's instructions. The samples were analyzed using a BD FACS CantoII instrument (BD Biosciences).

Cell cycle analysis by flow cytometry. Cell cycle analysis was conducted using the Cell Cycle Assay kit (cat. no. A411-01; Vazyme, Nanjing, China). The cells were harvested using $0.25 \%$ trypsin containing $1 \mathrm{mM}$ EDTA (Gibco) and fixed for $12 \mathrm{~h}$ in $70 \%$ ethanol at $4^{\circ} \mathrm{C}$. The fixed cells were then centrifuged at $1,200 \mathrm{x} \mathrm{g}$ for $15 \mathrm{~min}$ to remove the ethanol, washed twice with $3 \mathrm{ml}$ phosphate-buffered saline (PBS), re-suspended in $1 \mathrm{ml}$ PI staining solution $(20 \mu \mathrm{g} / \mathrm{ml}$ PI and $0.2 \mathrm{mg} / \mathrm{ml}$ RNase A in PBS) and incubated for $15 \mathrm{~min}$ at RT. The samples were subsequently analyzed using a BD FACS CantoII instrument (BD Biosciences). Twenty thousand events were collected from each sample. The percentages of cells in the G0/G1, S, and G2/M phases of the cell cycle were determined using ModFit LT v 3.3 software (BD Biosciences).

Invasion assay. Cell culture inserts $(8.0-\mu \mathrm{m}$ pore size; Millicell Cell Culture Insert; Millipore, Billerica, MA, USA) were pre-coated with $50 \mu \mathrm{g} / \mathrm{ml}$ Matrigel (BD Biosciences) on the upper surface. Cells were treated either with or without $50 \mu \mathrm{g} / \mathrm{ml} \mathrm{Au}-\mathrm{NP}$ solution for $24 \mathrm{~h}$, and the harvested cells $\left(2.5 \times 10^{5}\right)$ were then seeded into the upper compartment in $200 \mu \mathrm{l}$ RPMI-1640 containing $0.2 \%$ bovine serum albumin (Shanghai WeiHuan Biotech Co., Ltd.). The lower compartment was filled with $750 \mu 1$ RPMI-1640 containing 5\% FBS. The invasion assay was performed for $24 \mathrm{~h}$ in a $37^{\circ} \mathrm{C}$ incubator.

The culture medium in the upper and lower compartments of the chamber was then replaced with $4 \%$ formaldehyde to fix the cells. After incubation for $15 \mathrm{~min}$, the chambers were washed with PBS and stained with $0.1 \%$ crystal violet (Sinopharm Chemical Reagent Co., Ltd.) for $10 \mathrm{~min}$. After washing the chambers five times with deionized $\mathrm{H}_{2} \mathrm{O}$, the cells at the top of the Matrigel membrane were removed using cotton buds. Images of the cells remaining on the lower side, which were those that had transgressed through the membrane, were captured using a microscope (DM2500; Leica Microsystems, Wetzlar, Germany).

In addition, cells invaded through the membrane were quantified using the $\mathrm{QCM}^{\mathrm{TM}}$ 24-well Cell Invasion Fluorometric Assay (cat. no. ECM554; Millipore). This assay provides an efficient system for quantitative detection of cell invasion through a basement membrane model. SW579 cells, either in the absence (control) or in the presence of Au-NPs (5, $10,20,40,50$ or $60 \mathrm{~nm}$ ), were cultured in complete medium for $24 \mathrm{~h}$. Subsequently, cells were harvested, re-suspended in serum-free medium and seeded $\left(2.5 \times 10^{5}\right.$ cells $\left./ 250 \mu \mathrm{l}\right)$ into a plate chamber. RPMI-1640 containing 10\% FBS was used as chemoattractant added to the lower chamber. After incubation for $24 \mathrm{~h}$, cells remaining on the top of the membrane were removed and the inserts were placed in a fresh well. Cell 

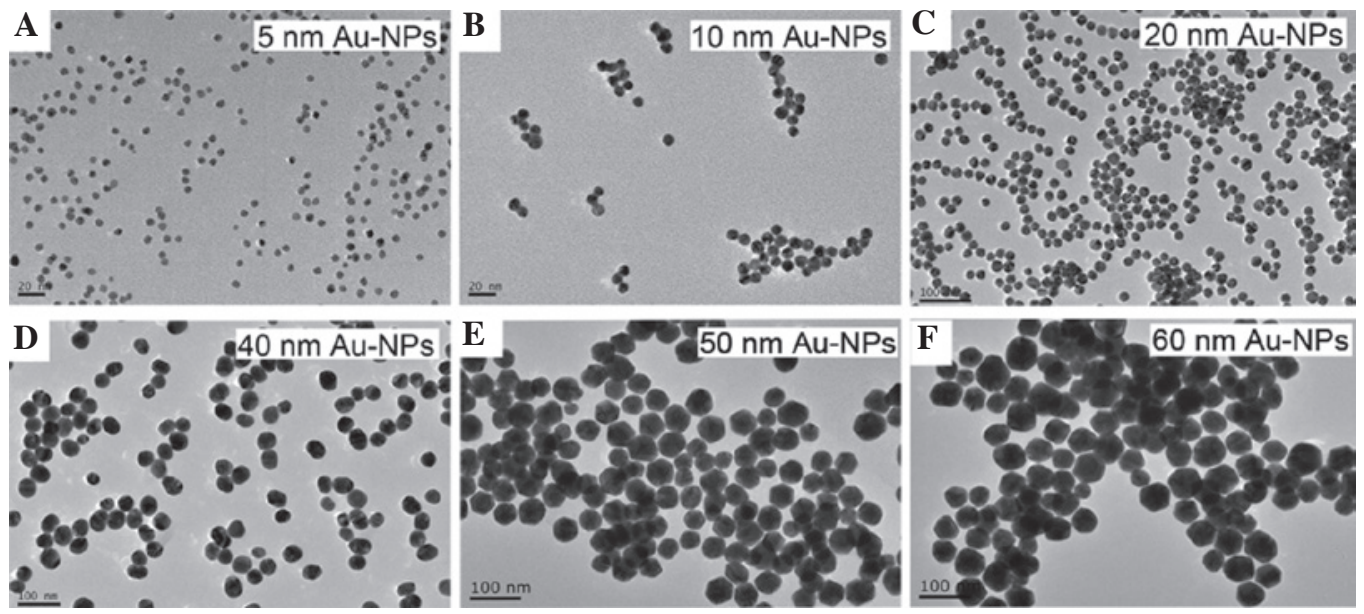

Figure 1. Characterization of the differently sized Au-NPs. Transmission electron microscopy images of Au-NPs with diameters of (A) $5 \mathrm{~nm}$, (B) $10 \mathrm{~nm}$, (C) $20 \mathrm{~nm}$, (D) $40 \mathrm{~nm}$, (E) $50 \mathrm{~nm}$ and (F) $60 \mathrm{~nm}$. Scale bars, $20 \mathrm{~nm}$ for A and B; $100 \mathrm{~nm}$ for C-F. NP, nanoparticle.
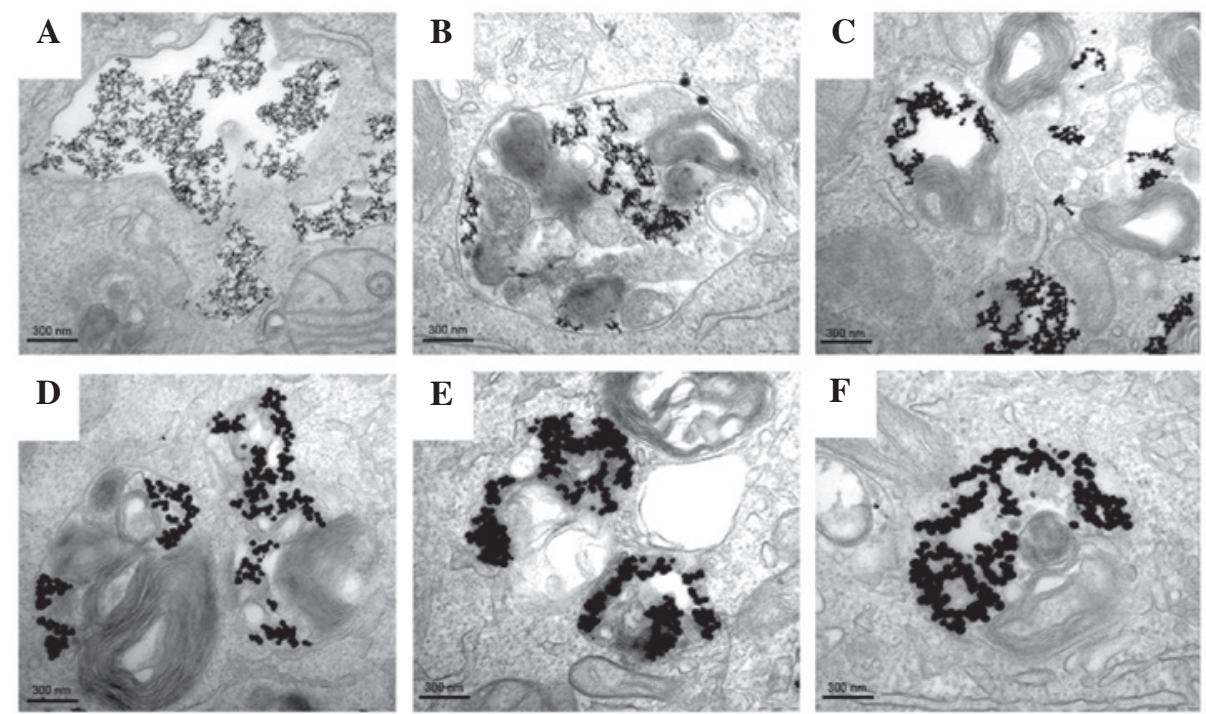

Figure 2. Transmission electron microscopy images of Au-NP uptake inside the cells. Images showing the internalization of $25 \mu \mathrm{g} / \mathrm{ml} \mathrm{Au}-\mathrm{NPs}$ with diameters of (A) $5 \mathrm{~nm}$, (B) $10 \mathrm{~nm}$, (C) $20 \mathrm{~nm}$, (D) $40 \mathrm{~nm}$, (E) $50 \mathrm{~nm}$ and (F) $60 \mathrm{~nm}$ into SW579 cells after treatment for $24 \mathrm{~h}$. Scale bars, $300 \mathrm{~nm}$. NP, nanoparticle.

detachment solution was added, followed by incubation at $37^{\circ} \mathrm{C}$ for $30 \mathrm{~min}$. After removing the inserts from the wells, lysis buffer/dye solution was added to the detached cells for $15 \mathrm{~min}$ at RT. Finally, the relative fluorescence of the stained lysates was assessed using a fluorescence plate reader (Synergy HT, Bio-Tek, Winooski, VT, USA) at 480/520 nm.

Reverse-transcription quantitative polymerase chain reaction (RT-qPCR) analysis. Total RNA was isolated from SW579 cells in each group using TRIzol reagent (Invitrogen; Thermo Fisher Scientific). Reverse transcription into cDNA (cat. no. R122-01; HiScript Q RT SuperMix for qPCR; Vazyme) was performed using $1 \mu \mathrm{g}$ total RNA with oligo dT primer, and PCR was performed using SYBR Green Mix (cat. no. Q111-02/03; AceO qPCR SYBR Green Master Mix; Vazyme) and ABI7300 Real-Time PCR System; Applied Biosystems; Thermo Fisher Scientific). The primer sequences were as follows: GAPDH forward, GGAGCCAAACGGGTCATCATCTC and reverse, GAGGGGCCATCCACAGTCTTCT; MMP2 forward, TGA
TCTTGACCAGAATACCATCGA and reverse, GGCTTG CGAGGGAAGAAGTT; MMP9 forward, GGCTACGTG ACCTATGACATCCT and reverse, TCCTCCCTTTCCTCC AGAACA (Invitrogen; Thermo Fisher Scientific). PCR was performed at $95^{\circ} \mathrm{C}$ for $5 \mathrm{~min}$, followed by $95^{\circ} \mathrm{C}$ for $30 \mathrm{sec}$ at $60^{\circ} \mathrm{C}$ for $30 \mathrm{sec}$ and $1 \mathrm{~min}$ at $70^{\circ} \mathrm{C}$ for 35 cycles. Melting curve analysis was performed to determine the specificity of the PCR products. The comparative Ct method (21) was used to evaluate the relative abundance of mRNA and target gene expression was normalized to that of GAPDH. Three independent experiments were performed.

Western blot analysis. SW579 cells $\left(1 \times 10^{6}\right)$ were placed in $75 \mathrm{~cm}^{2}$ culture flasks and treated with or without Au-NPs (5, 10, 20, 40, 50 and $60 \mathrm{~nm})$. After $24 \mathrm{~h}, 5-10 \times 10^{6}$ cells were harvested and lysed with ice-cold radioimmunoprecipitation assay lysis buffer (Sigma-Aldrich, St. Louis, MO, USA). Protein concentration was determined using Bicinchoninic Acid Protein Assay kit (cat. no. P0012A; Beyotime Institute 

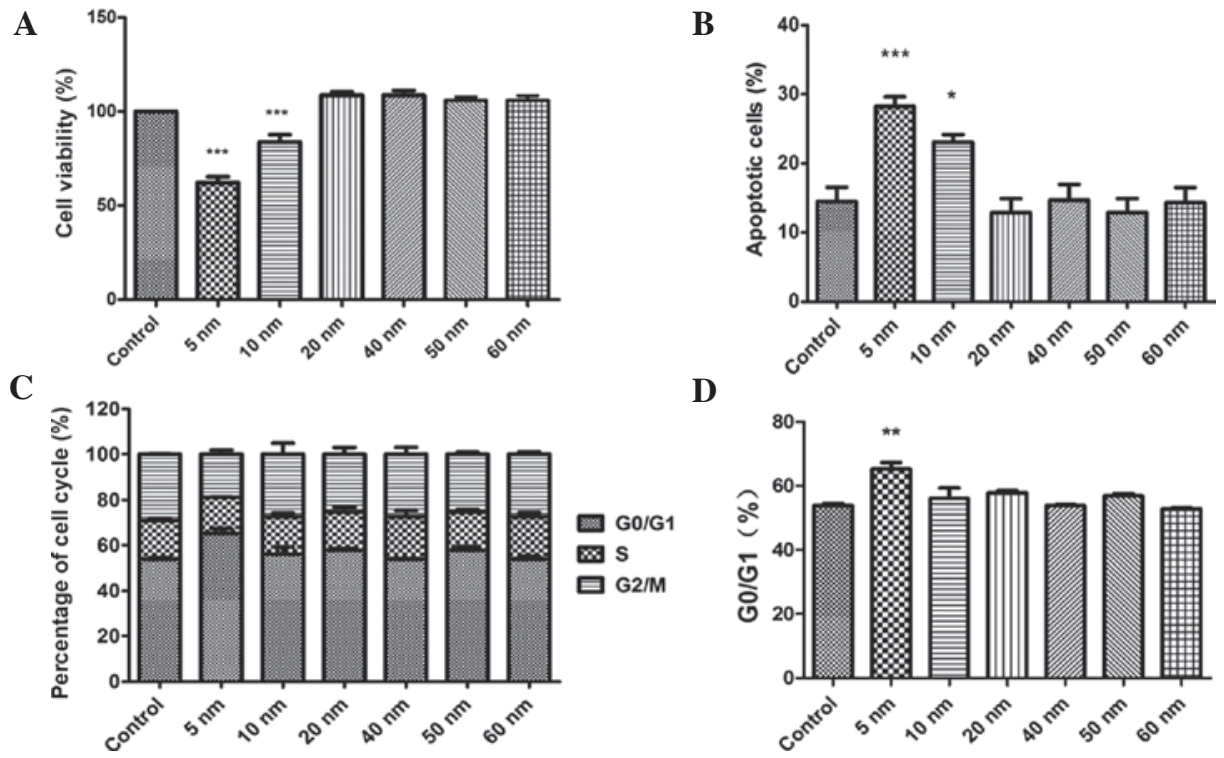

Figure 3. Comparison of the viability, apoptosis and cell cycle distribution of SW579 cells treated with Au-NPs. (A) Cell viability was calculated as the percentage of viable cells in the treatment groups compared to that in the untreated control. (B) Apoptotic rate of SW579 cells following treatment with Au-NPs (C) Cell cycle distribution of SW579 cells treated with differently sized Au-NPs and (D) proportion of cells in G0/G1 phase in the treatment groups. Values are expressed as the mean \pm standard deviation of three independent experiments. ${ }^{*} \mathrm{P}<0.05,{ }^{* *} \mathrm{P}<0.01,{ }^{* * *} \mathrm{P}<0.001$ vs. control. NP, nanoparticle.
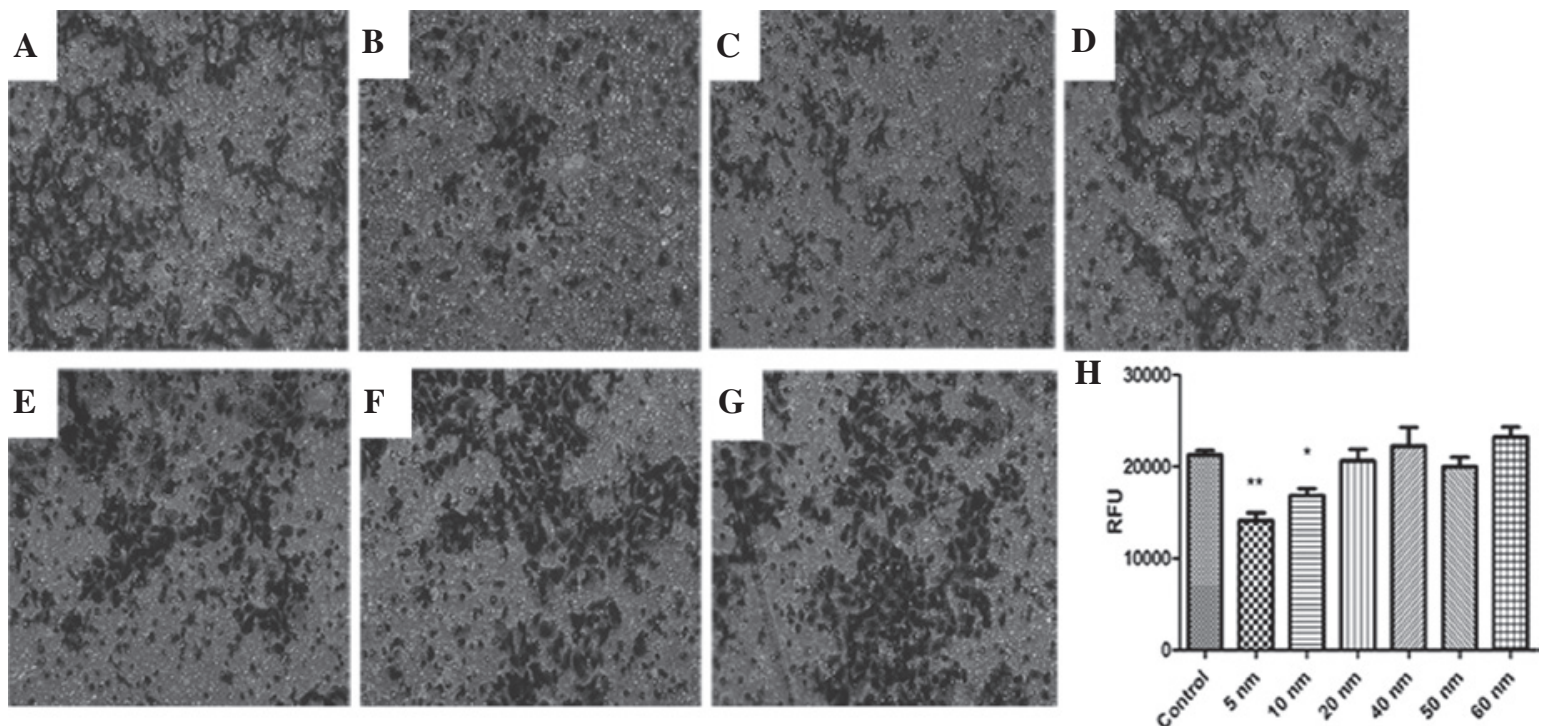

Figure 4. Effects of gold nanoparticles on the invasive capacity of SW579 cells. Images of SW579 cells that were (A) untreated or treated with nanoparticles sized (B) $5 \mathrm{~nm}$, (C) $10 \mathrm{~nm}$, (D) $20 \mathrm{~nm}$, (E) $40 \mathrm{~nm}$, (F) $50 \mathrm{~nm}$ or (G) $60 \mathrm{~nm}$ that transgressed through the membrane of a Transwell chamber. Cells were stained with crystal violet. (H) Fluorometric quantification of cell invasion using the QCM ${ }^{\mathrm{TM}}$ 24-well Cell Invasion Fluorometric Assay. Values are expressed as the mean \pm standard deviation of three independent experiments. ${ }^{*} \mathrm{P}<0.05,{ }^{* * *} \mathrm{P}<0.01$ vs. control. RFU, relative fluorescence units.

of Biotechnology, Shanghai, China). Equal amounts of protein $(50 \mu \mathrm{g})$ were separated by $10 \%$ SDS-PAGE and electrophoretically transferred onto polyvinylidene fluoride membranes (Millipore). Membranes were blocked with 5\% non-fat dry milk for $2 \mathrm{~h}$ and incubated overnight at $4^{\circ} \mathrm{C}$ with rabbit anti-MMP9 antibody (1:1,000; cat. no. ab38898; Abcam, Cambridge, MA, USA), rabbit anti-MMP2 antibody (1:1,000; cat. no. 13132; Cell Signaling Technology, Inc., Danvers, MA, USA), or mouse anti-GAPDH antibody (1:1,0000; cat. no. M20006; Abmart, Berkeley Heights, NJ, USA). Blots were washed five times with Tris-buffered saline containing $0.1 \%$ Tween 20 , and were then incubated with horseradish peroxidase-conjugated goat anti-rabbit (cat. no. H0912; dilution 1:1,000) or goat anti-mouse (cat. no. A8592; dilution 1:1,000) secondary antibodies (Sigma-Aldrich) and visualized with chemiluminescence reagents included in the ECL kit (Bio-Rad Laboratories, Inc.). GAPDH was used as the housekeeping gene control and the expression levels of the MMP2 and MMP9 were normalized to GAPDH. Immunoreactive bands were detected by enhanced chemiluminescence and quantified using a ChemiDoc XRS molecular imager (Bio-Rad Laboratories, Inc.).

Statistical analysis. GraphPad Prism 5.0 software for Windows (GraphPad, Inc., La Jolla, CA, USA) was used for all statistical analyses in this study. Values are expressed as the mean \pm standard deviation. Statistical comparisons were 

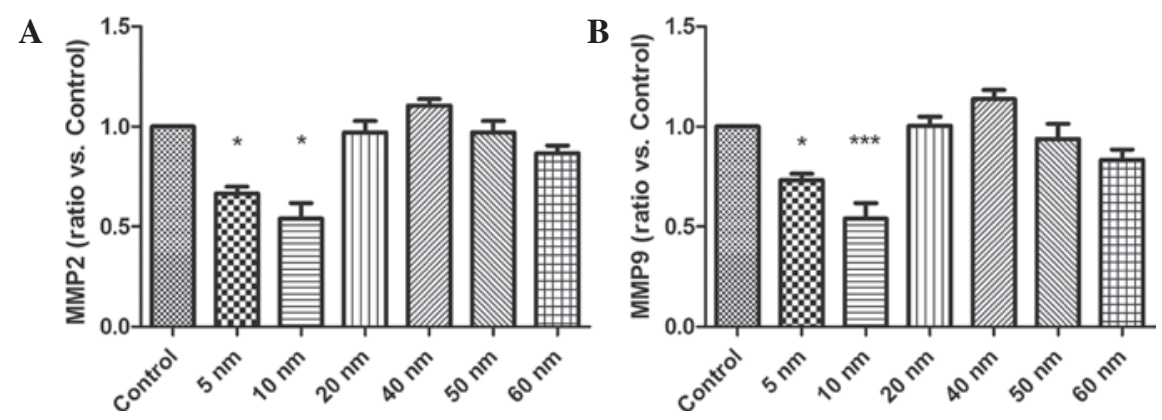

Figure 5. Fold changes in mRNA expression in SW579 cells treated with differently sized NPs according to reverse-transcription quantitative polymerase chain reaction analysis. (A) MMP2 and (B) MMP9 expression in SW579 cells after 24-h incubation with 5-nm, 10-nm, 20-nm, 40-nm, 50-nm or 60-nm Au-NPs. Values are expressed as the mean \pm standard deviation of three independent experiments. ${ }^{*} \mathrm{P}<0.05,{ }^{* * * *} \mathrm{P}<0.001$ vs. control. NP, nanparticles.
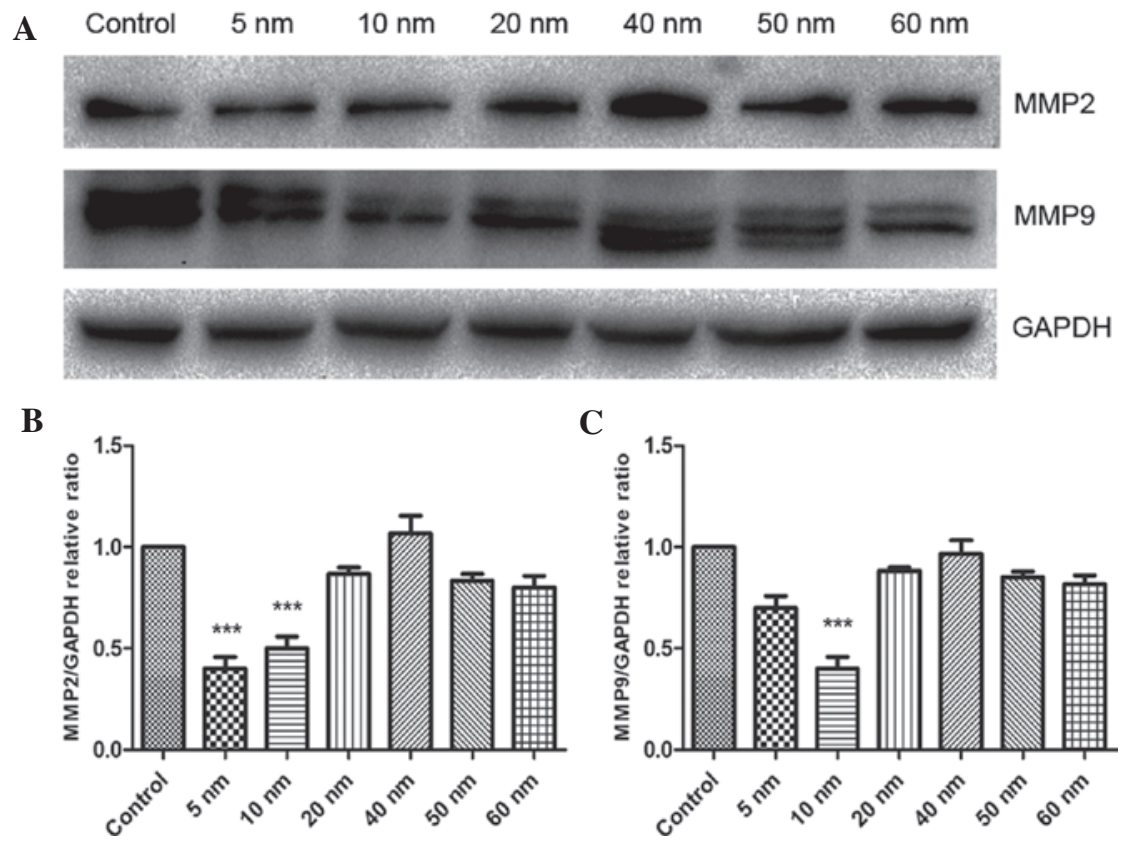

Figure 6. Western blot analysis of the expression levels of MMP2 and MMP9 in SW579 cells after Au-NP treatment for 24 h. (A) Representative blots showing the effect of Au-NPs treatment on the expression of MMP2 and MMP9 in SW579. (B) MMP2 and (C) MMP9 levels were quantified by determining the band densities relative to those of the control group with normalization to GAPDH. Values are expressed as the mean \pm standard deviation of three independent experiments. ${ }^{* * *} \mathrm{P}<0.001$ vs. control. MMP, matrix metalloproteinase; NP, nanoparticle.

performed using one-way analysis of variance, followed by the Dunnett's t-test for comparison with the control group. $\mathrm{P}<0.05$ was considered to indicate a statistically significant difference.

\section{Results}

Synthesis and characterization of Au-NPs. Au-NPs without any further modification were used in the present study. To explore the size-dependent effects of the nanoparticles, Au-NPs of six different sizes $(5,10,20,40,50$ or $60 \mathrm{~nm})$ were synthesized and characterized by TEM (Fig. 1). The particles exhibited a spherical shape and were uniform in size within each group.

Internalization of $\mathrm{Au}-\mathrm{NPs}$. To prove that Au-NPs were able to enter cells, SW579 cells were cultured in complete medium containing Au-NPs $(5,10,20,40,50$ or $60 \mathrm{~nm})$ for $24 \mathrm{~h}$ and visualized using TEM. Fig. 2 shows the internalization and distribution of Au-NPs with various sizes in SW579 cells.
Most of the particles appeared in vesicles or the perinuclear region within the cells.

Small-sized Au-NPs reduce the proliferation of SW579 cells, and induce apoptosis and cell cycle arrest. The CCK- 8 assay showed that only 5- and 10-nm Au-NPs exerted obvious inhibitory effects on the viability of SW579 cells and promoted apoptosis (Fig. 3A and B). In addition, only 5-nm Au-NPs caused significant cell cycle arrest in G0/G1 phase (Fig. 3C and D). By contrast, Au-NPs sized 20-60 nm showed no significant effects on the viability, apoptosis and cell cycle distribution of SW579 cells.

Small-sized Au-NPs reduce the invasive capacity of SW579 cells. The invasive capacity of SW579 cells was determined using a classic Transwell assay. As shown in Fig. 4, cell invasion was significantly suppressed by 5 - and 10-nm Au-NPs $(\mathrm{P}<0.05)$, while Au-NPs sized 20-60 nm did not significantly affect the invasiveness of SW579 cells. These 
findings indicated that the effects of Au-NPs on cell invasion may be size-dependent.

Small-sized Au-NPs inhibit the expression of MMP2 and MMP9 in SW579 cells. To elucidate the underlying mechanisms of the inhibitory effects of Au-NPS on SW579 cells, RT-qPCR analysis was performed to evaluate the mRNA expression of MMP2 and MMP9 in the presence of Au-NPs. The results showed that 5- and 10-nm Au-NPs markedly reduced the mRNA expression of MMP2 and MMP9 in SW579 cells (Fig. 5), while no significant effects were exerted by Au-NPs sized 20-60 nm.

Furthermore, the present study assessed the protein expression of MMP2 and -9 using western blot analysis. As shown in Fig. 6, treatment with 5-nm Au-NPs significantly decreased the protein expression of MMP2 $(\mathrm{P}<0.001)$ and obviously decreased the protein expression of MMP9. Furthermore, 10-nm Au-NPs significantly decreased the protein expression of MMP2 and MMP9 in SW579 cells ( $<<0.001)$, while no significant effects were observed for Au-NPs sized 20-60 nm.

\section{Discussion}

Major research efforts in biomedical nanotechnology have focused on drug delivery and biosensor applications. Although physicochemical and optoelectronic properties of inorganic nanoparticles have been studied in detail, their biological properties remain to be fully elucidated. Among them, Au-NPs have gained interest regarding their utilization in biomedical applications due to their low production cost and high synthetic accessibility (22-24). However, the basic knowledge regarding the interactions between nanomaterials and biological systems is required to be broadened prior to the clinical use of Au-NPs. Similar to the findings of several other studies $(25,26)$, the present study observed that Au-NPs were easily taken up by SW579 cells and localized in vesicles and the perinuclear regions. No marked differences were observed in cell uptake/localization, which may be due to the small sample size of the TEM selection.

The present study revealed that small Au-NPs with a diameter of 5 and $10 \mathrm{~nm}$ obviously inhibited the proliferation and induced apoptosis and G0/G1 phase cell cycle arrest of SW579 cells. By contrast, 20-60 nm-sized Au-NPs exerted no marked cytotoxic effects on SW579 cells, which is in line with the findings of previous studies. Arvizo et al (27) came to the conclusion that surface size, but not surface charge, has a significant effect on the biological effects of Au-NPs. However, other studies did not observe any cytotoxic effects of Au-NPs; for instance, Connor et al (11) reported that Au-NPs sized 4, 12 and $18 \mathrm{~nm}$ were not acutely toxic to K562 leukemia cells, and hypothesized that the previously observed cytotoxicity was an effect of the cetyltrimethyl ammonium bromide coating of the Au-NPs. Cui et al (28) even observed that Au-NPs promoted cell proliferation when accumulated on the cell surface instead of within the cells. Furthermore, Patra et al (29) demonstrated that Au-NPs did not universally target all cell types, which may explain for the controversy among the abovementioned studies.

To date, the underlying mechanisms of the anti-proliferative effects of Au-NPs have remained elusive. Most studies indicated that Au-NP-derived cytotoxicity is mainly based on the generation of reactive oxygen species $(30,31)$. Furthermore, $\mathrm{Au}-\mathrm{NPs}$ have been indicated to cause cell-morphological changes and cytoskeletal defects, leading to cell damage and inhibition of proliferation (29). In addition, Au-NPs have been demonstrated to interfere with the expression of genes associated with proliferation (32).

The present study revealed that the Au-NP-induced reduction of the invasive ability of SW579 cells was accompanied by a marked downregulation of MMP2 and MMP9 expression. The most important step in tumor metastasis is the invasion of tumor cells through the extracellular matrix (ECM). Tumor cells initiate invasion by adhering to and migrating along the blood or lymph vessel wall. MMPs, which are endopeptidases, are able to degrade ECM components, allowing tumor cells to access the vasculature and lymphatic systems $(33,34)$. MMPs have attracted much attention due to their ability to degrade type IV collagen, the basic component of the basement membrane. Increased expression of MMP9 in patients with thyroid carcinoma was shown to be correlated with a greater risk of advanced cancer $(35,36)$; therefore, drugs restraining the expression of MMPs may suppress tumor cell migration and invasion. It has been reported that MMP2 is highly expressed in human thyroid carcinoma $(37,38)$. Marecko et al (39) revealed that downregulation of MMP2 mRNA or protein markedly inhibited human thyroid carcinoma cell invasion. The present study found that 5- and 10-nm Au-NPs effectively suppressed the expression of MMP2 and MMP9 in SW579 cells, which partially explained for the inhibitory effects of the nanoparticles on tumor cell invasion. Since the downregulation of Au-NPs on MMP2 and MMP9 expression in SW579 cells indicated that small nanoparticles may own the ability to suppress the invasion of thyroid carcinoma cells, further in vivo studies are required to confirm the mechanisms.

To the best of our knowledge, the present study was the first to evidence the inhibitory effects of Au-NPs on thyroid carcinoma cell proliferation, viability and invasion in vitro, which contributes to the development of novel therapies for thyroid carcinoma utilizing Au-NPs. The present study suggested that the anti-cancer efficacy of unmodified Au-NPs largely depended on the particle size.

The present study assessed the inhibitory effects of unmodified Au-NPs of different sizes (5, 10, 20, 40, 50 and $60 \mathrm{~nm}$ ) on the proliferation, viability and invasion of thyroid carcinoma cells. NP size is an essential factor determining their efficacy with regard to the inhibition of cell proliferation and invasion. Only 5- and 10-nm Au-NPs were able to inhibit the proliferation and invasion of SW579 cells, which was indicated to be attributed to the downregulation of MMP2 and MMP9 expression. The present study provided useful information on the effects of Au-NPs on cell proliferation and invasion, which may contribute to the utilization of Au-NPs in thyroid carcinoma therapy.

\section{References}

1. Arvizo RR, Bhattacharyya S, Kudgus RA, Giri K, Bhattacharya R and Mukherjee P: Intrinsic therapeutic applications of noble metal nanoparticles: Past, present and future. Chem Soc Rev 41: 2943-2970, 2012. 
2. Dreaden EC, Alkilany AM, Huang X, Murphy CJ and El-Sayed MA: The golden age: Gold nanoparticles for biomedicine. Chem Soc Rev 41: 2740-2779, 2012.

3. Dykman LA and Khlebtsov NG: Gold nanoparticles in biology and medicine: Recent advances and prospects. Acta Naturae 3 . $34-55,2011$.

4. Huang X, Jain PK, El-Sayed IH and El-Sayed MA: Gold nanoparticles: Interesting optical properties and recent applications in cancer diagnostics and therapy. Nanomedicine (Lond) 2: 681-693, 2007.

5. Giljohann DA, Seferos DS, Daniel WL, Massich MD, Patel PC and Mirkin CA: Gold nanoparticles for biology and medicine. Angew Chem Int Ed Engl 49: 3280-3294, 2010.

6. Dreaden EC, Mackey MA, Huang X, Kang B and El-Sayed MA Beating cancer in multiple ways using nanogold. Chem Soc Rev 40: 3391-3404, 2011.

7. Arvizo RR, Saha S, Wang E, Robertson JD, Bhattacharya R and Mukherjee P: Inhibition of tumor growth and metastasis by a self-therapeutic nanoparticle. Proc Natl Acad Sci USA 110 6700-6705, 2013.

8. Palui G, Aldeek F, Wang W and Mattoussi H: Strategies for interfacing inorganic nanocrystals with biological systems based on polymer-coating. Chem Soc Rev 44: 193-227, 2015.

9. Hauser CA, Maurer-Stroh S and Martins IC: Amyloid-based nanosensors and nanodevices. Chem Soc Rev 43: 5326-5345, 2014.

10. Alkilany AM and Murphy CJ: Toxicity and cellular uptake of gold nanoparticles: What we have learned so far? J Nanopart Res 12: 2313-2333, 2010.

11. Connor EE, Mwamuka J, Gole A, Murphy CJ and Wyatt MD: Gold nanoparticles are taken up by human cells but do not cause acute cytotoxicity. Small 1: 325-327, 2005.

12. Liu Z, Wu Y, Guo Z, Liu Y, Shen Y, Zhou P and Lu X: Effects of internalized gold particles with respect to cytotoxicity and invasion activity in lung cancer cells. PLoS One 9: e99175, 2014

13. Ju D, Sun D, Xiu L, Meng X, Zhang C and Wei P: Interleukin-8 is associated with adhesion, migration and invasion in human gastric cancer SCG-7901 cells. Med Oncol 29: 91-99, 2012.

14. Machens A and Dralle H: Follicular thyroid carcinoma: Metastasis to the sternum or adjacent tumour invasion by continuity? Int J Clin Pract 61: 521, 2007.

15. Cvejic DS, Savin SB, Petrovic IM, Paunovic IR, Tatic SB and Havelka MJ: Galectin-3 expression in papillary thyroid carcinoma: Relation to histomorphologic growth pattern, lymph node metastasis, extrathyroid invasion, and tumor size. Head Neck 27: 1049-1055, 2005.

16. Liang H, Zhong Y, Luo Z, Huang Y, Lin H, Luo M, Zhan S, Xie K, Ma Y and Li QQ: Assessment of biomarkers for clinical diagnosis of papillary thyroid carcinoma with distant metastasis. Int J Biol Markers 25: 38-45, 2010.

17. Liang H, Zhong Y, Luo Z, Huang Y, Lin H, Zhan S, Xie K and Li QQ: Diagnostic value of 16 cellular tumor markers for metastatic thyroid cancer: An immunohistochemical study. Anticancer Res 31: 3433-3440, 2011.

18. Mlika M, Makhlouf C, Boudaya MS, Haddouchi C, Tritar F and Mezni F: Evaluation of the microvessel density and the expression of metalloproteases 2 and 9 and $\mathrm{ttf} 1$ in the different subtypes of lung adenocarcinoma in Tunisia: A retrospective study of 46 cases. J Immunoassay Immunochem 36: 111-118, 2015.

19. Sun C, Li Q, Hu Z, He J, Li C, Li G, Tao X and Yang A: Treatment and prognosis of anaplastic thyroid carcinoma: Experience from a single institution in China. PLoS One 8: e80011, 2013.

20. GF: Controlled nucleation for the regulation of the particle size in monodisperse gold suspensions. Nature 241: 20-22, 1973.

21. Cikos S, Bukovská A and Koppel J: Relative quantification of mRNA: Comparison of methods currently used for real-time PCR data analysis. BMC Mol Biol 8: 113, 2007.
22. Khlebtsov N and Dykman L: Biodistribution and toxicity of engineered gold nanoparticles: A review of in vitro and in vivo studies. Chem Soc Rev 40: 1647-1671, 2011.

23. Mesbahi A: A review on gold nanoparticles radiosensitization effect in radiation therapy of cancer. Rep Pract Oncol Radiother 15: 176-180, 2010.

24. Levy R, Shaheen U, Cesbron Y and Sée V: Gold nanoparticles delivery in mammalian live cells: A critical review. Nano Rev 1: 2010.

25. Zhang S, Gao H and Bao G: Physical principles of nanoparticle cellular endocytosis. ACS Nano 9: 8655-8671, 2015.

26. Oh N and Park JH: Endocytosis and exocytosis of nanoparticles in mammalian cells. Int J Nanomedicine 9 (Suppl 1): 51-63, 2014

27. Arvizo R, Bhattacharya R and Mukherjee P: Gold nanoparticles: Opportunities and challenges in nanomedicine. Expert Opin Drug Deliv 7: 753-763, 2010.

28. Cui W, Li J, Zhang Y, Rong H, Lu W and Jiang L: Effects of aggregation and the surface properties of gold nanoparticles on cytotoxicity and cell growth. Nanomedicine 8: 46-53, 2012.

29. Patra HK, Banerjee S, Chaudhuri U, Lahiri P and Dasgupta AK: Cell selective response to gold nanoparticles. Nanomedicine 3 : 111-119, 2007.

30. Thakor AS, Paulmurugan R, Kempen P, Zavaleta C, Sinclair R, Massoud TF and Gambhir SS: Oxidative stress mediates the effects of Raman-active gold nanoparticles in human cells. Small 7: 126-136, 2011.

31. Pan Y, Leifert A, Ruau D, Neuss S, Bornemann J, Schmid G, Brandau W, Simon U and Jahnen-Dechent W: Gold nanoparticles of diameter $1.4 \mathrm{~nm}$ trigger necrosis by oxidative stress and mitochondrial damage. Small 5: 2067-2076, 2009.

32. Yang Y, Qu Y and Lü X: Global gene expression analysis of the effects of gold nanoparticles on human dermal fibroblasts. J Biomed Nanotechnol 6: 234-246, 2010.

33. Hamano Y, Zeisberg M, Sugimoto H, Lively JC, Maeshima Y, Yang C, Hynes RO, Werb Z, Sudhakar A and Kalluri R: Physiological levels of tumstatin, a fragment of collagen IV alpha3 chain, are generated by MMP-9 proteolysis and suppress angiogenesis via alphaV beta3 integrin. Cancer Cell 3: 589-601, 2003.

34. Egeblad M and Werb Z: New functions for the matrix metalloproteinases in cancer progression. Nat Rev Cancer 2: 161-174, 2002.

35. Borrello MG, Alberti L, Fischer A, Degl'innocenti D, Ferrario C, Gariboldi M, Marchesi F, Allavena P, Greco A, Collini P, et al: Induction of a proinflammatory program in normal human thyrocytes by the RET/PTC1 oncogene. Proc Natl Acad Sci USA 102: 14825-14830, 2005.

36. Mesa C Jr, Mirza M, Mitsutake N, Sartor M, Medvedovic M, Tomlinson C, Knauf JA, Weber GF and Fagin JA: Conditional activation of RET/PTC3 and BRAFV600E in thyroid cells is associated with gene expression profiles that predict a preferential role of BRAF in extracellular matrix remodeling. Cancer Res 66: 6521-6529, 2006.

37. Sanii S, Saffar H, Tabriz HM, Qorbani M, Haghpanah V and Tavangar SM: Expression of matrix metalloproteinase-2, but not caspase- 3 , facilitates distinction between benign and malignant thyroid follicular neoplasms. Asian Pac J Cancer Prev 13: 2175-2178, 2012

38. Delektorskaia VV, Smirnova EA, Ponomareva MV, Pavlova TV and Pavlov IA: Expression of matrix metalloproteinases 2 and 9 and their tissue inhibitors 1 and 2 in papillary thyroid cancer: An association with the clinical, morphological and ultrastructural characteristics of a tumor. Arkh Patol 72: 3-6, 2010 (In Russian).

39. Marecko I, Cvejić D, Tatić S, Dragutinović V, Paunović I and Savin S: Expression of matrix metalloproteinase-2 and its tissue inhibitor-2 in fetal and neoplastic thyroid tissue and their significance as diagnostic and prognostic markers in papillary carcinoma. Cancer Biomark 11: 49-58, 2011. 